\title{
Increased Tissue Factor Expression is an Independent Predictor of Mortality in Clear Cell Carcinoma of the Kidney
}

\author{
Daniel D’Oliveira Silva, Jorge Antonio Pastro Noronha, Vinicius Duval da Silva, Gustavo Franco Carvalhal
}

Department of Urology, Pontifical Catholic University of Rio Grande do Sul, RS, Brazil

\section{ABSTRACT}

Purpose: Increased expression of tissue factor (TF), a primary initiator of the extrinsic coagulation pathway, has been associated with a worse prognosis in a variety of solid tumors. We report for the first time the correlation of the immunohistochemical expression of tissue factor with clinical and pathological outcomes in clear cell carcinomas of the kidney.

Materials and Methods: immunohistochemical expression of tissue factor was evaluated in 58 paraffin-embedded samples of clear cell carcinomas of the kidney treated at the same university hospital, that was correlated with clinical and pathological variables and with overall survival.

Results: high intensity tissue factor expression (TF area $>10 \mu \mathrm{m}^{2}$ ) was observed in $22.4 \%$ of the tumors (13 patients), and was an important predictor of overall mortality, both in univariate and multivariate analysis $(\mathrm{p}<0.05)$. Median overall survival for both groups was 66 months; 78.2 months for patients in the group of lower TF expression and 27.5 months for patients in the group of higher TF expression (log rank $\mathrm{p}<$ 0.001). The hazard ratio for mortality was 9.7 (CI 3.7-25.6) for tumors with increased TF expression.

Conclusions: Increased immunohistochemical expression of TF was an important independent predictor of mortality in a contemporary cohort of patients with clear cell carcinoma of the kidney. Further studies are necessary to define the role of TF in clinical practice.

\section{ARTICLE INFO}

Key words:

Kidney; Carcinoma; Neoplasms;

Histological Techniques

Int Braz J Urol. 2014; 40: 499-506

Submitted for publication:

November 21, 2013

Accepted after revision:

March 22, 2014

\section{INTRODUCTION}

Renal cell carcinomas are responsible for $2-3 \%$ of all solid malignancies, and their incidence and mortality rates have been increasing over the last decades. It is a highly lethal neoplasm, with estimated 64,000 new cases and 13,000 deaths in the U.S. for 2012 (1). Clear cell carcinomas represent $85-90 \%$ of all renal cell cancers, and are usually associated with increased mortality (2). Most renal tumours diagnosed nowadays are small solid lesions, incidentally discovered during imaging tests such as abdominal ultrasoun- ds or computerized tomography scans, which when adequately treated may yield up to 95\% 5 -years cancer specific survival rates (3). However, a substantial proportion of cases (up to 30\%) are still diagnosed in the metastatic setting, in which cure is rarely possible and less than $5-10 \%$ of 5-year cancer-specific survival is expected (4). Many pre and postoperative prognostic factors have been reported in renal cell carcinomas, such as tumour size, clinical and pathological stage, Fuhrman grade, among others. However, none of these factors, isolated or in association can predict with certainty which tumours will eventually 
recur and affect patients' survival (4). Thus, a continuous search for novel prognostic markers in renal cell carcinomas is justified, to better predict prognosis and to plan more efficacious, individualized therapeutic strategies.

The association between cancer, coagulation and thrombosis was first reported in 1865, when Armand Trousseau described an increased rate of thrombotic events in patients with gastrointestinal tumors (5). Further studies revealed that one of the pivotal agents involved in this association was tissue factor, or thromboplastin (6). A trans-membrane glycoprotein, tissue factor (TF) is responsible for the initiation of the extrinsic coagulation pathway. TF is abundant in the sub-endothelial layer of blood vessels and in tissues surrounding most internal organs, in which it supposedly acts as a natural haemostatic barrier (7). When exposed, TF initiates the coagulation cascade, resulting in fibrin formation. Increased expression of TF was also described in tumor cells of a variety of solid neoplasms, including melanomas (8), breast (9), prostate (10), lung (11), ovarian (12), gastrointestinal (13), bladder and renal cancers (14). In some studies, increased TF expression was correlated to worse clinical outcomes (8-13). We have recently reported on the positive association between increased TF expression and poor prognosis in patients with Wilms tumors (15). We now describe the expression of TF by immunohistochemistry in clear cell carcinomas of patients with a minimum follow-up of five years after the initial treatment, correlating TF expression with clinical and pathological variables, and with overall survival.

\section{MATERIALS AND METHODS}

Our initial cohort was composed of 60 patients with clear cell carcinoma of the kidney diagnosed and treated at a University hospital in southern Brazil (Hospital Sao Lucas) from 2004 to 2007 with either partial or radical nephrectomy. We excluded from analysis two patients in whom paraffin blocks were unavailable or considered inadequate for analysis due to insufficient tumour tissue; thus, our final study group consisted of fifty-eight patients $(\mathrm{N}=58)$. We considered as variables age at the time of diagnosis, gender, Fuhrman grade, TNM stage (2010) and TF expression. Ove- rall and cancer specific survival were considered the main outcome measures.

Patients' age at the time of diagnosis was registered in months and years. For statistical analysis, we considered three months as 0.25 , six months as 0.50 , and nine months as 0.75 years.

Histological grade was ranked in four categories (I-IV) as defined by Fuhrman (16), and the same pathologist (VDS) reviewed all pathology slides. The 2010 TNM was used for both clinical and pathological staging. The attending surgeon determined the surgical approach (partial or radical nephrectomy) in each case.

\section{Immunohistochemistry}

Immunohistochemical analysis was performed in formalin-fixed, paraffin-embedded tissue samples. Five-micron sections were cut onto coated slides and deparaffinated by routine techniques. Analysis of TF expression was performed in a blinded manner, using a Zeiss Axioskop $40^{\circledR}$ (Carl Zeiss, Oberkochen, Germany) optical microscope at a magnification of $100 \mathrm{X}$ and Image Pro Plus $4.5 .1^{\circledR}$ image analysis software (Media Cybernetics, Rockville, U.S.A.). Samples of prostate carcinoma were used as positive and negative controls of TF expression.

Immunohistochemical expression of TF was evaluated with a quantitative methodology, selecting and digitizing microscopic fields where there was positive staining at $100 \mathrm{X}$ magnification without imaging superposition (17). The number of images selected for each case varied from one to five. Each image file had a total area of $361,918 \mu \mathrm{m}^{2}$. In all images captured, analyses were performed with a 24-bit colour selection method, with the creation of RGB colour reference files, which were applied to all images to define the measurement area, as shown in Figure-1 (18). Results were expressed in $\mu \mathrm{m}^{2}$. We defined high or low immunohistochemical expression of TF according to the median of the areas measured in all cases $\left(10 \mu \mathrm{m}^{2}\right)$. Three independent observers agreed with the selection process of the areas examined in all cases.

Clinical, pathological, and follow-up data were obtained through chart reviews and, whenever required, telephone contacts or active residence search. 
Figure 1 - TF staining in renal cell carcinoma. A) Low staining for TF expression (area $<10 \mu \mathrm{m}^{2}$ ) in RCC tumour; B) High intensity of staining for TF (area $>10 \mu \mathrm{m}^{2}$ ) in RCC tumour (reduced from X100). C) and D) images captured with 24 bit select colours (RGB) both in low and high intensity of staining for TF. The selected areas are marked in red.

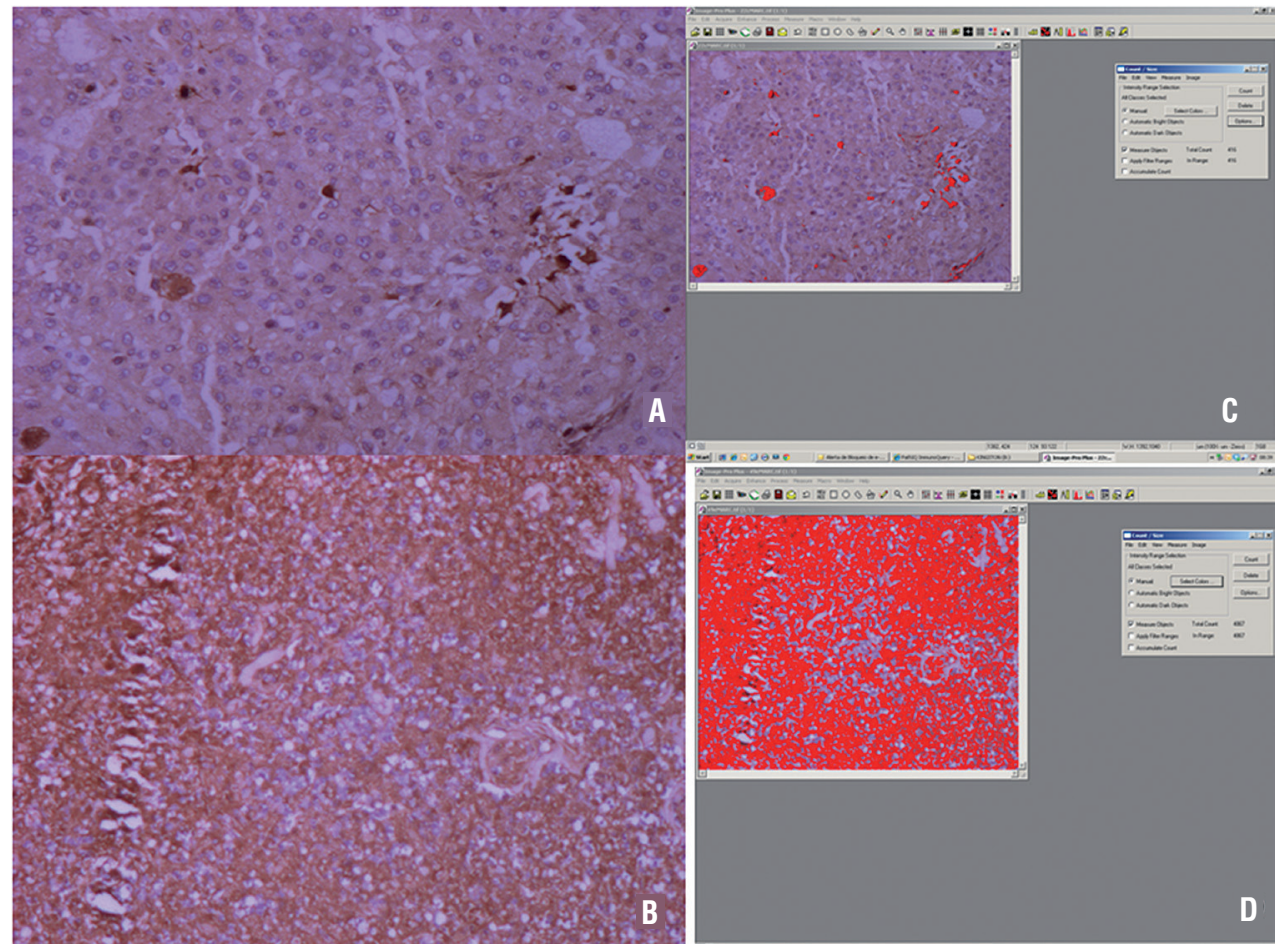

\section{Statistical Analysis and Ethics}

Continuous data were described using mean and standard deviation. For asymmetric data we used median and inter-quartile range. Categorical data were expressed using counts and percentages. Baseline features were compared using Student's $t$ test for continuous data and chi-square tests for categorical data. A survival analysis was conducted using Kaplan-Meier method followed by log rank test for comparison between groups. A multivariable analysis based on the Cox regression model was used to adjust for confounding $(p<0.005)$. Data were analyzed using SPSS version $18.0^{\circledR}$. The study protocol was reviewed and approved by the ethics committee at the University Hospital.

\section{RESULTS}

Clinical and pathological variables of the patients in our cohort are shown in Table-1 $(\mathrm{N}=58)$.
Most patients were male ( $\mathrm{n}=40 ; 69.1 \%)$, and mean age was 58.8 years (31-91 years). Mean tumour size was $6.1 \mathrm{~cm}$ (range $2.1-19.0 \mathrm{~cm}$ ). Regarding Fuhrman, 13 patients (22.4\%) were grade 1, 28 (48.0\%) were grade 2, 10 (17.2\%) were grade 3 and 7 (12.0\%) were grade 4. At diagnosis, 28 patients (50.0\%) were TNM stage I, six (10.7\%) were stage II, 15 (26.7\%) were stage III, and seven (12.5\%) were stage IV. TNM data was missing for two patients. Necrosis was present in 32 samples (55.1\%), absent in 24 (41.3\%) and it was not reported in 2 cases (3.4\%). Stratification of the immunohistochemical expression of TF was done according to the intensity of TF staining, with a cut off point of $10 \mathrm{~mm}^{2}$.

The groups of patients with low and high intensity of TF staining were homogeneous for age, gender and tumour size (all $\mathrm{p}>0.05$; Table-1). $\mathrm{Pa}-$ tients with high intensity of TF staining had a greater proportion of less differentiated tumours (Fuhrman grades 3 and $4 ; \mathrm{p}<0.05)$ and of higher pathological stages (TNM stages III and IV; $p<0.002$ ). 
Table 1 - Patients characteristics.

\begin{tabular}{|c|c|c|c|}
\hline \multirow[b]{2}{*}{ Characteristics } & \multicolumn{2}{|c|}{ Tissue Factor } & \multirow[b]{2}{*}{$P$} \\
\hline & $\begin{array}{c}\geq 10 \mu m^{2} \\
n=13\end{array}$ & $\begin{array}{c}<10 \mu m^{2} \\
n=45\end{array}$ & \\
\hline Age, years & $58.8 \pm 8.8$ & $58.8 \pm 14.4$ & $0.994^{[a]}$ \\
\hline Male sex, n (\%) & $9(69.2)$ & $31(68.9)$ & $0.632^{[\mathrm{b}]}$ \\
\hline Tumour size, cm & $7.2 \pm 2.2$ & $5.8 \pm 3.2$ & $0.149^{[a]}$ \\
\hline Fuhrman grade, $n$ (\%) & & & $0.019^{[b]}$ \\
\hline 1 & $2(15.4)$ & $11(24.4)$ & \\
\hline 2 & $4(30.8)$ & $24(53.3)$ & \\
\hline 3 & $2(15.4)$ & $8(17.8)$ & \\
\hline 4 & $5(38.5)$ & $2(4.4)$ & \\
\hline TNM stage, $n(\%)^{*}$ & & & 0.002 \\
\hline I & $1(8.3)$ & 27 (61.4) & \\
\hline ॥ & $2(16.7)$ & $4(9.1)$ & \\
\hline III & $5(41.7)$ & $10(22.7)$ & \\
\hline IV or more & $4(33.3)$ & $3(6.8)$ & \\
\hline
\end{tabular}

Data are presented as mean \pm standard deviation or counts (\%).

TNM = TNM staging classification for renal cell carcinoma. * TNM data missing for 2 patients. $\mathbf{p}$ : statistical significance, [a] = Student's $t$ test, [b] = Fisher's exact test.

In our cohort, 21 patients died during follow-up (36.2\%). Seven patients (12.0\%) were metastatic at diagnosis, all of whom have died of the disease, twelve developed recurrences during follow-up, and subsequently died $(20.7 \%)$, one $(1.7 \%)$ died of unrelated causes during follow-up, and one (1.7\%) died in the postoperative period of complications associated with the surgical procedure. Forty-five patients had low intensity expression of TF (77.6\%), while 13 patients had high intensity expression of TF (22.4\%) in the immunohistochemical analysis. Median global and cancer specific survival for both groups was, respectively, 66 and 68 months; 78.2 and 81.5 months for patients in the group of lower TF expression and 27.5 and 27.5 months for the patients in the group of higher TF expression (log rank $\mathrm{p}<0.001$; Figure-2). Increased TF expression was statistically associated to decreased survival, as shown in Figure-2.

To further assess the impact of the intensity of TF staining as a significant predictor of mortali- ty, we performed a multivariable regression analysis adjusted for some of the reported prognostic factors in renal cell carcinomas, such as patients' age, tumour size, gender, TNM stage, Fuhrman grade and the SSIGN score from Mayo Clinic. We chose not to include individual data of necrosis in the multivariate analysis, since it was presented in the SSIGN score which includes necrosis. In the multivariable model, increased TF expression remained an important independent prognostic factor for increased mortality (Table-2).

\section{DISCUSSION}

In spite of a recent shift towards earlier stage at presentation, mortality rates from clear cell carcinoma of the kidneys are increasing. Such trend may be explained by the fact that a considerable proportion of cases are advanced at diagnosis, and it is known that even small lesions of less than 
Figure 2 - Overall and cancer specific survival curves for patients with lower and higher TF staining.
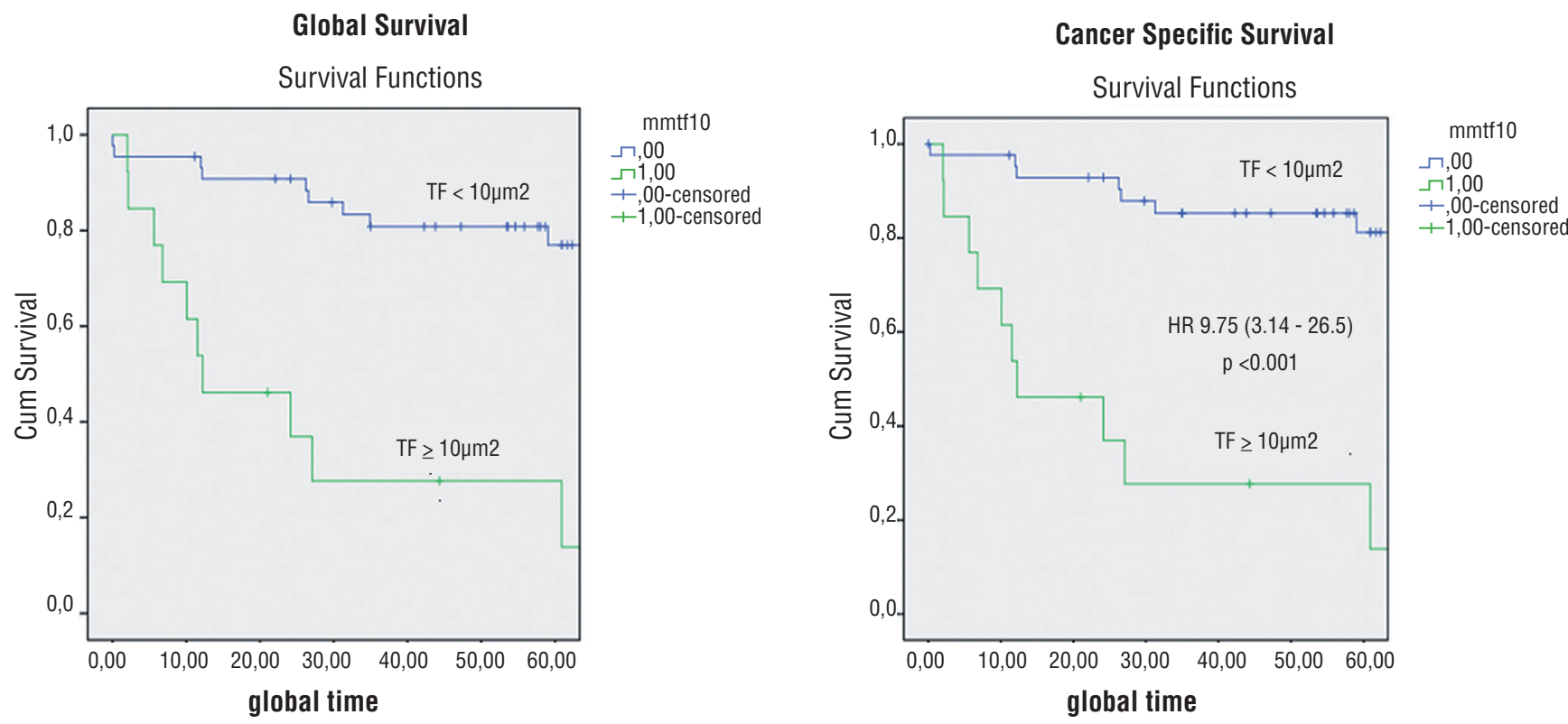

Table 2 - Association of high intensity tissue factor expression and selected variables with death among renal cancer patients (patients $=58$, events $=21$ ).

\begin{tabular}{lcccccc}
\hline & \multicolumn{3}{c}{ Univariate Analysis } & \multicolumn{3}{c}{ Multivariable Analysis } \\
\cline { 2 - 7 } Variable & $\mathrm{HR}$ & $95 \% \mathrm{Cl}$ & $\mathrm{p}$ & $\mathrm{HR}^{[a]}$ & $95 \% \mathrm{Cl}$ & $\mathrm{p}$ \\
\hline Tissue factor exp. $\geq 10 \mu \mathrm{m}^{2}$ & 9.75 & 3.71 to 25.64 & $<0.001$ & 4.03 & 1.07 to 15.14 & 0.039 \\
Age, years & 1.03 & 0.98 to 1.05 & 0.351 & 1.04 & 1.00 to 1.08 & 0.074 \\
Female sex & 0.55 & 0.18 to 1.66 & 0.267 & 0.33 & 0.07 to 0.89 & 0.033 \\
Fuhrman grade $\geq 3$ & 2.48 & 0.97 to 6.30 & 0.056 & 0.61 & 0.18 to 2.08 & 0.437 \\
Tumour size, cm & 1.09 & 0.98 to 1.21 & 0.130 & 1.04 & 0.71 to 1.12 & 0.356 \\
SSIGN score $\geq 6$ & 12.25 & 4.41 to 34.00 & $<0.001$ & 9.09 & 2.33 to 35.42 & 0.001 \\
TNM stage III or more & 8.58 & 2.49 to 29.58 & 0.001 & 5.30 & 1.21 to 23.18 & 0.026 \\
\hline
\end{tabular}

[a] = Hazard ratio obtained in a Cox proportional hazards model including all listed factors; $\mathbf{p}$ : statistical significance; $\mathbf{9 5} \% \mathbf{C l}$ : 95\% confidence interval.

$4 \mathrm{~cm}$ in diameter present with metastasis in $4-7 \%$ of cases (19). In our study, $12 \%$ of patients had metastatic disease at presentation. This is similar to most international series $(20,21)$, but compares favourably with the statistics published by the Brazilian National Institute of Cancer, in which roughly $20 \%$ of cases were metastatic at diagnosis (22).
Most our cases were treated by radical nephrectomy (77.5\%), whereas partial nephrectomies were performed in $22.5 \%$. The proportion of partial nephrectomies has been increasing over the years globally in face of smaller tumors at diagnosis; however, partial nephrectomies are still outnumbered by radical nephrectomies in most series, 
and ours is no exception (23). Our perioperative mortality rate was $1.7 \%(1 / 58)$, similar to most recently published surgical series of radical and partial nephrectomies (around 0.9\%) (24), and we have to consider that one of our patients who died preoperatively was an octogenarian. In one of the largest series of nephrectomies in octogenarians, Berger et al. (25) reported a 38\% morbidity rate and a 3.3\% operative mortality rate, and advised caution in indicating renal surgery at this age range. Most of our patients had good clinical status with almost no comorbidities.

In spite of many prognostic factors available for renal cell carcinoma, it still not possible to accurately identify which patient will have a favourable or an unfavourable outcome. The best tools to predict mortality from renal cell carcinoma yield c-indexes (concordance indexes) of $88 \%$ (20). Clearly, new markers need to be unveiled in order to improve prognostic accuracy in renal cell cancer.

Increased immunohistochemical expression of TF was associated with worse outcomes and mortality rates in many solid neoplasms (melanomas, breast, prostate, lung, ovarian, gastrointestinal) (8-13). Additionally, we have recently published that in Wilms' tumours, the most common kidney neoplasm in children, an increased immunohistochemical expression of TF was the most important predictor of tumor recurrence and mortality (15). In renal cell carcinomas, to our knowledge this is the first study reporting TF expression by immunohistochemistry in the indexed literature. In 2003, Forster et al. (14) have published a study in which they reported TF expression by an enzyme linked immunosorbent assay (ELISA) test and by a LightCycler ${ }^{\mathrm{TM}}$ polymerase chain reaction (PCR) assay both in malignant and benign tissues of patients with prostate, bladder and renal cell carcinomas (18 patients with RCC). With these methodologies, they have found a greater expression of TF in the normal tissues in comparison to the neoplastic samples. In the same study, the authors tested for serum TF expression in 75 patients with RCC and 92 normal age-matched controls, and could not detect a significant difference (14). However, the authors did not correlate their findings with clinical outcomes.
We believe that our findings are important since we present for the first time the correlation of TF expression with clinical outcomes in RCC. Moreover, we have shown that, although expressed in a minority of RCCs (22.4\%), TF was a significant predictor of mortality in our cohort, with a very high hazard ratio (HR 9.7; CI 3.7-25.6). When tested for possible confounding factors in the multivariable analysis, the importance of TF expression in predicting mortality was reduced, but remained significant (HR 4.03; CI 1.07-15.1). The possibility of a new prognostic factor in RCC is by itself a novelty, but we believe that the existing prediction models may further increase their accuracy by including this marker, which should be a subject of future studies.

A potential therapeutic role for anti-TF therapies is currently being investigated in a variety of ways. It is believed that tumour TF may induce the coating of tumour cells with fibrin, trapping the cells in the microvasculature and enhancing the process of hematogenous metastasis. In this regard, at least two experimental studies in mouses have shown that blockage of the TF pathway with anti-TF antibodies or with tissue factor protein-inhibitor (TFPI) has reduced the incidence of pulmonary metastases $(26,27)$. Additionally, it is believed that the coupling of TF with coagulation factor VIIa and protease-activated receptor 2 (PAR2) drives angiogenesis through the production of factors such as the vascular endothelial growth factor (VEGF). The blockage of this specific pathway is the target of two new drugs currently being tested in phase II in pancreatic cancer and other solid tumours $(28,29)$. Positive results in these trials may enhance the therapeutic arsenal for cancers in which TF plays an important role, such as RCC.

The methodology employed in the quantification of the immunohistochemical expression of TF was new to our group. In previous studies, we used a semi-quantitative method of limited reproducibility, in which the observers determined scores based on the intensity of TF expression through visual analysis of the slides, from grades I (0-25\% of cells intensely expressing TF) through IV $(>75 \%)(10,15)$. In the present study we opted to perform a quantitative method internationally 
validated which measures an area unit $\left(\mu \mathrm{m}^{2}\right)(30)$ The availability of ever more sophisticated software for image analysis such as the Image Pro Plus $^{\circledR}$ allows for fewer measurement biases and more accurate reproducibility.

Our study has several caveats that may compromise the generalization of its findings. First, it is a retrospective study, with the implied limitations in data collection. Second, the immunohistochemical staining was performed in paraffın-embedded tissue stored at the department of pathology for at least five years. Third, the small number of patients [58] may obviate definitive conclusions. Additional studies with prospective data collection, complementary molecular methodologies and a larger number of patients are needed to validate and further advance on our findings.

\section{CONCLUSIONS}

Increased TF expression by immunohistochemistry was an important independent prognostic factor of mortality in a contemporary cohort of patients with renal cell carcinoma. Further studies are necessary to define its role in clinical practice.

\section{ABBREVIATIONS}

$\mathrm{TF}=$ tissue factor

$\mathrm{RCC}=$ renal cell carcinoma

$\mathrm{RBG}=$ red, blue and green

ELISA = enzyme linked immunosorbent assay

$\mathrm{PCR}=$ polymerase chain reaction

TFPI $=$ tissue factor protein inhibitor

PAR2 $=$ protease-activated receptor 2

VEGF $=$ vascular endothelial growth factor

\section{CONFLICT OF INTEREST}

None declared.

\section{REFERENCES}

1. Siegel R, Naishadham D, Jemal A: Cancer statistics, 2012. CA Cancer J Clin. 2012; 62: 10-29.

2. Novara G, Martignoni G, Artibani W, Ficarra V: Grading systems in renal cell carcinoma. J Urol. 2007; 177: 430-6.
3. Sun M, Shariat SF, Cheng C, Ficarra V, Murai M, Oudard S, et al.: Prognostic factors and predictive models in renal cell carcinoma: a contemporary review. Eur Urol. 2011; 60: 644-61.

4. Tsui $K H$, Shvarts 0 , Smith RB, Figlin RA, deKernion JB, Belldegrun A: Prognostic indicators for renal cell carcinoma: a multivariate analysis of 643 patients using the revised 1997 TNM staging criteria. J Urol. 2000; 163: 1090-5; quiz 1295.

5. Anand M, Brat DJ: Oncogenic regulation of tissue factor and thrombosis in cancer. Thromb Res. 2012; 129(Suppl 1): S46-9.

6. Kasthuri RS, Taubman MB, Mackman N: Role of tissue factor in cancer. J Clin Oncol. 2009; 27: 4834-8.

7. Kocatürk B, Versteeg $\mathrm{HH}$ : Tissue factor isoforms in cancer and coagulation: may the best isoform win. Thromb Res. 2012; 129(Suppl 1): S69-75.

8. Mueller BM, Reisfeld RA, Edgington TS, Ruf W: Expression of tissue factor by melanoma cells promotes efficient hematogenous metastasis. Proc Natl Acad Sci U S A. 1992; 89: 11832-6.

9. Ueno T, Toi M, Koike M, Nakamura S, Tominaga T: Tissue factor expression in breast cancer tissues: its correlation with prognosis and plasma concentration. $\mathrm{Br} \mathrm{J}$ Cancer. 2000; 83: 164-70.

10. Abdulkadir SA, Carvalhal GF, Kaleem Z, Kisiel W, Humphrey PA, Catalona WJ, et al.: Tissue factor expression and angiogenesis in human prostate carcinoma. Hum Pathol. 2000; 31: 443-7.

11. Sawada M, Miyake S, Ohdama S, Matsubara O, Masuda S, Yakumaru K, et al.: Expression of tissue factor in non-smallcell lung cancers and its relationship to metastasis. $\mathrm{Br} \mathrm{J}$ Cancer. 1999; 79: 472-7.

12. Han LY, Landen CN Jr, Kamat AA, Lopez A, Bender DP, Mueller $\mathrm{P}$, et al.: Preoperative serum tissue factor levels are an independent prognostic factor in patients with ovarian carcinoma.J Clin Oncol. 2006; 24: 755-61.

13. Yu JL, May L, Lhotak V, Shahrzad S, Shirasawa S, Weitz JI, et al.: Oncogenic events regulate tissue factor expression in colorectal cancer cells: implications for tumor progression and angiogenesis. Blood. 2005; 105: 1734-41.

14. Förster $Y$, Meye A, Albrecht $S$, Kotzsch M, Füssel $S$, Wirth MP, et al.: Tissue specific expression and serum levels of human tissue factor in patients with urological cancer. Cancer Lett. 2003; 193: 65-73.

15. Maciel EO, Carvalhal GF, da Silva VD, Batista EL Jr, Garicochea B: Increased tissue factor expression and poor nephroblastoma prognosis. J Urol. 2009; 182: 1594-9.

16. Fuhrman SA, Lasky LC, Limas C: Prognostic significance of morphologic parameters in renal cell carcinoma. Am J Surg Pathol. 1982; 6: 655-63.

17. Vartanian RK, Weidner $\mathrm{N}$ : Correlation of intratumoral endothelial cell proliferation with microvessel density (tumor angiogenesis) and tumor cell proliferation in breast carcinoma. Am J Pathol. 1994; 144: 1188-94. 
18. Larsen JO, Gundersen HJ, Nielsen J: Global spatial sampling with isotropic virtual planes: estimators of length density and total length in thick, arbitrarily orientated sections. J Microsc. 1998; 191: 238-248.

19. Lughezzani G, Jeldres C, Isbarn H, Perrotte P, Shariat SF, Sun $M$, et al.: Tumor size is a determinant of the rate of stage T1 renal cell cancer synchronous metastasis. J Urol. 2009; 182: 1287-93.

20. Karakiewicz PI, Suardi N, Capitanio U, Isbarn H, Jeldres C, Perrotte $\mathrm{P}$, et al.: Conditional survival predictions after nephrectomy for renal cell carcinoma. J Urol. 2009; 182: 2607-12.

21. Frank I, Blute ML, Cheville JC, Lohse CM, Weaver AL, Zincke $\mathrm{H}$ : An outcome prediction model for patients with clear cell renal cell carcinoma treated with radical nephrectomy based on tumor stage, size, grade and necrosis: the SSIGN score. J Urol. 2002; 168: 2395-400.

22. Ornellas AA, Andrade DM, Ornellas P, Wisnescky A, Schwindt $A B$ : Prognostic factors in renal cell carcinoma: analysis of 227 patients treated at the Brazilian National Cancer Institute. Int Braz J Urol. 2012; 38: 185-94.

23. Kim SP, Shah ND, Weight CJ, Thompson RH, Moriarty JP, Shippee ND, et al.: Contemporary trends in nephrectomy for renal cell carcinoma in the United States: results from a population based cohort. J Urol. 2011; 186: 1779-85.

24. Abdollah F, Sun M, Thuret R, Schmitges J, Shariat SF, Perrotte P, et al.: Mortality and morbidity after cytoreductive nephrectomy for metastatic renal cell carcinoma: a population-based study. Ann Surg Oncol. 2011; 18: 2988-96.

25. Berger J, Fardoun T, Brassart E, Capon G, Bigot P, Bernhard JC, et al.: Detailed analysis of morbidity following nephrectomy for renal cell carcinoma in octogenarians. J Urol. 2012; 188: 736-40.
26. Amirkhosravi A, Meyer T, Chang JY, Amaya M, Siddiqui F, Desai $H$, et al:: Tissue factor pathway inhibitor reduces experimental lung metastasis of B16 melanoma. Thromb Haemost. 2002; 87: 930-6.

27. Mueller BM, Ruf W: Requirement for binding of catalytically active factor VIla in tissue factor-dependent experimental metastasis. J Clin Invest. 1998; 101: 1372-8.

28. Hedrick E. Study of safety and tolerability of PCl27483 in patients with pancreatic cancer patients receiving treatment with gemcitabine (www.clinicaltrials gov;Bethesda,MD:National Library of Medicine). Available at: http://clinicaltrials.gov/ct2/show/study/NCT01020006. Last assessed in January, 022012.

29. Wong HC: A study of ALT-386 in combination with gemcitabine for locally advanced or metastatic solid tumors (www.clinicaltrials.gov; Bethesda,MD:National Library of Medicine). Available at: http://clinicaltrials.gov/ct2/show/ study/NCT01325558. Last assessed in January, 022012.

30. Irion LC, Prolla JC, Hartmann AA, Irion KL, Da Silva VD: Angiogenesis in non-small cell lung cancer: microvessel area in needle biopsy in vascular tumor density. Anal Quant Cytol Histol. 2008; 30: 83-91.

Correspondence address: Daniel D’Oliveira Silva, MD Department of Urology,

Pontifical Catholic University of Rio Grande do Sul Rua Ipiranga, 6690/601

Porto Alegre, RS, 90000-000, Brazil E-mail: danieldosilva@yahoo.com.br 